\title{
The importance of preoperative topical non-steroidal antiinflammatory agents in cataract surgery- an open label prospective randomised comparative study
}

\author{
Minj A. ${ }^{1}$, Satapathy $\mathbf{J .}^{2}$, Kumar A. ${ }^{3}$ \\ ${ }^{1}$ Dr. Anita Minj, Associate Professor, ${ }^{2}$ Dr. Jasmita Satapathy, Associate Professor, ${ }^{3}$ Dr. Atish Kumar, Junior Resident, all \\ authors are affiliated with Department of Ophthalmology, IMS and SUM hospital, Bhubaneswar, Odisha, India.
}

Corresponding Author: Dr. Jasmita Satapathy, MBBS, DNB (Ophthalmology), Associate Professor, Department of Ophthalmology, IMS and SUM Hospital, Bhubaneswar, Odisha, India. E-mail: jasmitasatapathy@soa.ac.in

\begin{abstract}
Introduction: Intraoperative miosis is a problem which can lead to various complications that may adversely affect the outcome of cataract surgery. Topical non-steroidal anti-inflammatory drugs (NSAIDs) have been found to be helpful in reducing the intraoperative miosis. We tried to compare the effectiveness of two such molecules bromfenac and nepafenac. Objective: To compare the effectiveness of topical bromfenac $(0.09 \%)$ and nepafenac $(0.1 \%)$ in maintaining mydriasis and controlling immediate post-operative inflammation in cataract surgery. Methods: This is a prospective, randomised, open-label, comparative study of patients with senile cataract posted for cataract extraction and intra-ocular lens (IOL) implantation. The patients were randomised into 3 groups: topical moxifloxacilin $0.5 \%$ alone (control group or group A), topical bromfenac $0.09 \%+$ moxifloxacilin $0.5 \%$ (group B) and topical nepafenac $0.1 \%+$ moxifloxacilin $0.5 \%$ (group C). The drops were started one day before surgery. Mean pupil diameter was measured before starting surgery and after implanting IOL. Slit lamp examination was done on first postoperative day to look for anterior chamber reaction. The values were compared among the 3 groups. Results: The total loss of mean pupillary diameter was significant $(\mathrm{p}<0.0001)$ in control group $(25.87 \%)$ as compared to bromfenac $(3.51 \%)$ and nepafenac $(3.81 \%)$ group. Post-operative inflammation was significantly less $(\mathrm{p}<0.0001)$ in bromfenac and nepafenac group as compared to that of control group. Loss of mydriasis and post-operative inflammation was similar in both bromfenac and nepafenac group. Conclusion: Both bromfenac and nepafenac given topically prior to cataract surgery are equally effective in maintaining mydriasis during surgery as well as in controlling immediate postoperative inflammation.
\end{abstract}

Keywords: Intraoperative miosis, Topical NSAIDs, Topical bromfenac, Topical nepafenac, Post cataract surgery inflammation

\section{Introduction}

Cataract contributed to a worldwide $33.4 \%$ of all blindness [1]. In developing countries like India, every year many cataract surgeries are done to meet the backlogs. There are many factors which influence the outcome of such high-volume cataract surgeries. Adequate mydriasis is one of the most important factors especially while doing high volume cataract surgeries. It reduces the time of surgery and also facilitates favourable outcome. A well dilated pupil helps a surgeon to see better and as much as possible. This improves the outcome even in difficult cases as zonular dehiscence, capsular tear and vitreous loss can be detected early.

Manuscript received: $8^{\text {th }}$ September 2019

Reviewed: $18^{\text {th }}$ September 2019

Author Corrected: $24^{\text {th }}$ September 2019

Accepted for Publication: $27^{\text {th }}$ September 2019
Commonly topical tropicamide with phenylephrine is used to achieve good pupillary dilatation. In a normal eye this dilation is maintained. But during surgery traumatised ocular tissue activates phospholipase A23 and liberates arachidonic acid metabolites and platelet activating factors. Arachidonic acid forms the substrate for further reaction by cyclooxygenase and lipooxygenase pathways. In these pathways prostaglandins and leukotrienes are produced [2]. The pro- inflammatory Prostaglandins cause vasodilatation and increase vascular permeability. Thus, they play a key role in ocular inflammation, cystoid macular edema and changes in intraocular pressure (IOP) [3].

Prostaglandins also cause smooth muscle contraction in iris leading to miosis during cataract surgery. 
Topical NSAIDs is found to be effective in inhibiting the inflammatory cascade that occurs during cataract surgery and maintains mydriasis [4]. They act by blocking the conversion of arachidonic acid into prostaglandins, prostacyclin and thromboxane by cyclooxygenase enzymes (COX) -1 and/ or COX- 2 [5].

For inflammatory tissue response $\mathrm{COX}-2$ enzyme is more prevalent than COX-1 and therefore the efficacy of NSAIDs is determined by their potency to inhibit the action of COX-2 enzyme [6].

Many drugs have proven their effectiveness to maintain the mydriasis. Food and Drug Administration approved NSAIDs used for cataract surgery include ketorolac, diclofenac, bromfenac and nepafenac [7]. However, the latter two drugs are used now a days more often for various ophthalmic causes.

Bromfenac $0.09 \%$ ophthalmic solution acts by inhibiting cyclooxygenase enzyme, mainly COX-2 and has a low affinity for COX-1. It is very well absorbed through cornea and reaches aqueous humour where its action is maintained for at least 12 hours [8]. Hence twice daily dose is sufficient to control inflammation.

Nepafenac $0.1 \%$ ophthalmic solution is a prodrug which rapidly penetrate through cornea and hydrolyzed in the intraocular tissues to amfenac, which is a potent inhibitor of COX-1 and COX-2 enzyme.

Its prodrug nature reduces corneal toxicity and enhances tissue penetration [9]. Thus nepafenac acts as a target specific NSAID which inhibits prostaglandin production effectively in ocular tissues both in anterior and posterior segment [10].

This study is aimed to compare the effectiveness of topical bromfenac and nepafenac when used preoperatively in maintaining intra-operative mydriasis and also in controlling immediate post-operative inflammation.

\section{Materials and Methods}

This is a hospital based prospective, randomized, openlabel comparative study carried out in the department of Ophthalmology over a period of 1 year from May 2018 to April 2019, after taking due permission from Hospital Ethics committee.

A total of 180 patients were included in the study. Informed written consent was taken from each patient before enrollment for the study.
Inclusion criteria: Patients between 40 to 85 years of age, of either sex having senile cataract who were admitted for cataract surgery with Intra Ocular Lens implantation.

Exclusion criteria: Patients with complicated cataract, dacryocystitis, any active ocular inflammation, previous intraocular surgery, intra- operative complications, glaucoma, known allergy to NSAID, systemic medications causing intra-operative floppy iris syndrome and patients on topical or systemic NSAID and / or steroid therapy 1 month prior to surgery.

The study subjects were randomly divided into 3 groups, 60 patients in each group.

Group A received topical Moxifloxacin 0.5\% 6 hourly.

Group B received Bromfenac 0.09\% 12 hourly along with topical moxifloxacin 6 hourly.

Group C received Nepafenac $0.1 \% 8$ hourly along with topical moxifloxacin 6 hourly.

The drops were started one day prior to surgery and put once before giving peribulbar anesthesia on the day of surgery. Before surgery all patients underwent complete ophthalmic examination including visual acuity, IOP measurement by applanation tonometer, Slit- lamp biomicroscopy, dilated fundoscopy and detailed systemic examination. On the day of surgery, pupil was dilated using tropicamide $(0.8 \%)$ and phenylephrine (5\%) eye drops, 1 drop every 10-15 minutes starting 1 hour prior to surgery till full dilatation.

Phacoemulsification or Manual small incision cataract surgery was performed by a single surgeon for all the cases. Horizontal and vertical pupillary diameter was measured, and the mean was taken at the beginning of surgery and after implantation of IOL by using a sterile caliper over the cornea.

On first post-op day, all patients underwent slit-lamp examination. Ocular inflammation was assessed by anterior chamber reaction and grading of aqueous cell and flare was done according to the Standardization of Uveitis Nomenclature.

Statistical analysis: The data thus collected were entered in an Excel file along with the demographic characteristics. The data was presented as mean \pm SD or patient's number and percentage. Statistical analysis was done by using ANOVA. $p$-value $<0.05$ was considered as statistically significant. 


\section{Results}

Table 1 represented the demographic profile of 180 patients, 60 in each group. The baseline demographic profile was comparable in all the 3 groups. The average age of the patients was $63.62 \pm 9.56$ years and $52.2 \%$ were females.

Table-1: Demographic profile of patients in all groups.

\begin{tabular}{|c|c|c|c|c|}
\hline Parameter & Group A & Group B & Group C & $P$ value \\
\hline \multicolumn{4}{|l|}{ Age in years } & \multirow{2}{*}{ Insignifican } \\
\hline Mean \pm SD & $63.87 \pm 8.36$ & $63.43 \pm 10.51$ & $63.58 \pm 9.81$ & \\
\hline \multicolumn{4}{|l|}{ Gender } & \multirow{3}{*}{ Insignifican } \\
\hline Male & 30 & 32 & 27 & \\
\hline Female & 30 & 28 & 33 & \\
\hline \multicolumn{4}{|l|}{ Laterality } & \multirow{3}{*}{ Insignificant } \\
\hline Right eye & 33 & 31 & 30 & \\
\hline Left eye & 27 & 29 & 30 & \\
\hline
\end{tabular}

Table 2 represented mean pupillary diameter before and after surgery. Before starting surgery, the average pupil diameter was almost similar in all the groups. The total loss of mydriasis from beginning to the end of surgery was statistically significant in group A $(1.78 \pm 1.17 \mathrm{~mm})$, as compared to group $\mathrm{B}(\mathrm{p}<0.0001)$ and group $\mathrm{C}(\mathrm{p}<0.0001)$. The difference of pupil size was almost similar in both bromfenac $(0.25 \pm 0.88 \mathrm{~mm})$ and nepafenac $(0.26 \pm 0.86 \mathrm{~mm})$ group. This indicates both nepafenac and bromfenac are equally effective in maintaining mydriasis during cataract surgery.

Table-2: Comparison of mean pupil diameter in all groups.

\begin{tabular}{|l|c|c|c|c|}
\hline Parameter & Group A & Group B & Group C & P value \\
\hline Mean pupil diameter before Surgery (in mm) & 6.88 & 7.13 & 6.83 & 6.56 \\
\hline $\begin{array}{l}\text { Mean pupil diameter at the end of surgery } \\
\text { (in mm) }\end{array}$ & 5.10 & 6.88 & $0.26 \pm 0.86$ & $<0.0001$ \\
\hline $\begin{array}{l}\text { Total loss of mydriasis } \\
\text { (in mm) }\end{array}$ & $1.78 \pm 1.17$ & $0.25 \pm 0.88$ & & \\
\hline \% age of loss of mydriasis & 25.87 & 3.51 & 3.81 & \\
\hline
\end{tabular}

Table 3 describes the comparison of anterior chamber reaction on $1^{\text {st }}$ post-operative day among all the groups. In group A 31 (51.66\%) cases had anterior chamber cells, out of which 9 cases had grade 2 cells. 12 cases in group B and 22 cases in group C had AC cells. Only 3 cases in nepafenac group and none of the cases in bromfenac group had grade 2 cells. Immediate Post-operative inflammation on $1^{\text {st }}$ day was statistically significant $(p=0.017)$ in control group as compared to both bromfenac and nepafenac group. None of the groups had cells more than grade 2 . There was no drug induced serious adverse effect and no intraoperative complications in any of the groups. However, 2 patients in bromfenac group had blood clot over iris on $1^{\text {st }}$ postoperative day which subsided on next visit without any extra medication.

Table-3: Comparison of AC cells on $1^{\text {st }}$ post-operative day among all 3 groups.

\begin{tabular}{|c|c|c|c|c|}
\hline Grading of AC cells & Group A & Group B & Group C & P value \\
\cline { 1 - 4 } No cells & 29 & 48 & 38 & \\
\cline { 1 - 4 } Cells & & & & 0.017 \\
(Significant)
\end{tabular}

Pre and post-operative comparison of mydriasis among the three groups was represented through Figure 1. 
Original Research Article

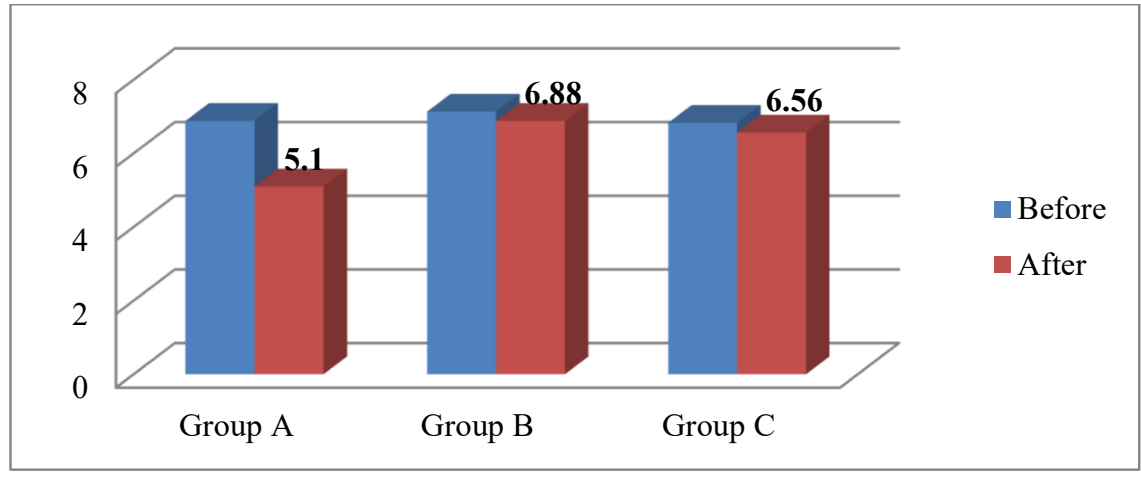

Figure-1: Comparison of mydriasis before and after surgery among 3 groups.

\section{Discussion}

According to the Rapid assessment of avoidable blindness survey 2006-2007, complication of cataract surgery accounts for $3.0 \%$ of blindness in India. Therefore, along with the other causes of avoidable blindness we need to reduce the complication of cataract surgery related blindness.

Adequate pupillary dilatation is the key to success for cataract surgery. Miosis due to surgical trauma during cataract surgery makes the eye more vulnerable to serious complications like zonular dialysis, posterior capsule rupture and vitreous loss. Topical non-steroidal anti-inflammatory drugs are found to be effective in maintaining mydriasis during cataract surgery [4]. This has been widely accepted as an important role of NSAIDs to improve visualization during cataract surgery. In addition to that they also give beneficial effect in controlling post-operative pain, inflammation and cystoid macular edema. Many studies showed the efficacy of different topical NSAIDs in reducing surgical trauma induced miosis. Several studies have compared the efficacy of different drugs of the same group.

A study done by Roberts et al, comparing the efficacy of diclofenac $0.01 \%$ and flurbiprofen $0.03 \%$ to inhibit surgically induced miosis in cataract surgery, found both the drugs are equally effective [11]. Gimbel et al compared flurbiprofen $0.03 \%$ and indomethacin $1 \%$ and found no difference in their efficacy in maintaining mydriasis during cataract surgery [12].

Topical ketorolac tromethamine $0.5 \%$ was found to be more effective inhibitor of miosis during phacoemulsification surgery and gives stable mydriatic effect throughout surgical procedure than topical flurbiprofen $0.03 \%$ in a study done by Solomon et al [13]. A study was done by Atanis et al, in which they found topical nepafenac $0.1 \%$ was more effective than topical ketorolac $0.5 \%$ in maintenance of mydriasis [14]. Saumya et al analyzed the effect of topical nepafenac $0.1 \%$ and topical flurbiprofen $0.03 \%$ in preventing miosis during small incision cataract surgery and concluded that nepafenac provides more stable mydriatic effect than flurbiprofen [15]. However, in another study by Sanjana et al there was no statistically significant difference in the efficacy between nepafenac and flurbiprofen [16].

Bromfenac and nepafenac are the two NSAIDs mostly used topically for many ophthalmological conditions now a days. Very few studies have been done to compare the efficacy of both the drugs. In our study we have compared the efficacy of topical bromfenac $0.09 \%$ and nepafenac $0.1 \%$ and found both are superior in maintaining mydriasis during cataract surgery than control group. There was a significant decrease in average pupil diameter in control group (25.78\%) as compared to bromfenac $(3.51 \%)$ and nepafenac $(3.81 \%)$ group.

The results of our study was similar to a study done by Bansal $\mathrm{G}$ et al, in which they have reported $6 \%$ loss of mydriasis in nepafenac group and $5 \%$ loss in bromfenac group, as opposed to control group that had $22 \%$ loss of mydriasis [17].

Their study also suggested no significant difference in the efficacy of nepafenac and bromfenac in maintaining mydriasis during cataract surgery. Similar result was reported in a study by Cervantes-Coste et al. They found prophylactic use of nepafenac $0.1 \%$ was more effective in maintaining mydriasis as compared to control group [18]. Another study by Chen $\mathrm{H}$ et al showed pre-operative use of topical bromfenac sodium $0.1 \%$ in Femtosecond laser assisted cataract surgery was effective in maintaining intraoperative mydriasis as compared to control (placebo) group [19]. 


\section{Original Research Article}

Many surgeons are now opting to use NSAID ophthalmic solutions preoperatively and post operatively to reduce intraoperative pain and postoperative inflammation.

Compared with other ophthalmic NSAIDs, bromfenac and nepafenac were shown to be more potent as well as safe in controlling postoperative ocular pain and inflammation [20, 21, 22, 23].

In the present study, it was observed that the immediate post-operative inflammation was significantly less in both group B and C as compared to group A (control group). Silverstein SM et al concluded in their study that topical bromfenac one day prior to surgery and continued for 14 days following surgery, is clinically safe and effective in the treatment of ocular inflammation and the reduction of pain associated with cataract surgery [24].

However, we have not continued using topical NSAIDs after surgery. Patients have received topical steroid in tapering dose in the post-operative phase to control inflammation. Though literature gives enough evidence about the efficacy of topical NSAIDs, a number of studies have proved steroid is best in controlling postoperative inflammation [23].

Topical NSAIDs was discontinued in the post-operative phase to minimise the risk of potential corneal complications including corneal infiltrate and erosion, though reported infrequently [25].

Some NSAIDs including bromfenac can increase bleeding time due to interference with platelet aggregation. Studies have reported that topical NSAIDs may increase the risk of bleeding of ocular tissues including hyphema following cataract surgery [25]. In the present study it was observed that two cases in bromfenac group with blood clot over iris at collarette on first postoperative day which resolved completely on its own after one week.

Limitations: To be included in both the manual SICS and Phacoemulsification. However, no subgroup analysis to compare the outcome of use of topical NSAIDs between the two groups was done.

\section{Conclusion}

Topical NSAIDs are useful in maintaining mydriasis during cataract surgery. Both bromfenac and nepafenac are equally effective in preventing intraoperative miosis and can minimise immediate postoperative inflammation.

\section{What this study adds to existing knowledge?}

Though both bromfenac and nepafenac are equally effective in preventing intraoperative miosis, bromfenac can be a preferred drug as the frequency of dosing is less than nepafenac.

Also, we found that pre-operative topical NSAIDs can minimise immediate postoperative inflammation even when it is used 1 day prior to surgery.

\section{Author's contribution}

Dr. Anita Minj: Conceptualisation, patient selection, data analysis, compilation

Dr. Jasmita Satapathy: Randomisation, patient selection, data entry, data analysis, compilation

Dr. Atish Kumar: Data collection, data entry

Funding: Nil, Conflict of interest: Nil

Permission from IRB: Yes

\section{References}

1. Khairallah M, Kahloun R, Bourne R, Limburg H, Flaxman SR, Jonas JB, et al. Number of people blind or visually impaired by cataract worldwide and in world regions, 1990 to 2010. Invest Ophthalmol Vis Sci. 2015; 56 (11):6762-6769. doi: 10.1167/iovs.15-17201.

2. Chen L, Yang G and Grosser T. Prostanoids and inflammatory pain. Prostaglandins Other Lipid Mediat. 2013;104-105:58-66.doi:10.1016/j.prostaglandins.2012. 08.006

3.Colin J. The Role of NSAIDs in the Management of postoperative ophthalmic Inflammation. Drugs. 2007; 67(9):1291-308. doi: 10.2165/00003495-200767 09000004

4. Ahuja M, Dhake A.S, Sharma S.K and Majumdar D.K. Topical ocular delivery of NSAIDs. Am Asso Pharm Sciences J. 2008; 10(2): 229-241.doi: 10.1208/ s12248-008-9024-9

5. Kim SJ, Flach AJ, Jampol LM. Nonsteroidal antiinflammatory drugs in ophthalmology. Surv Ophthalmol. 2010; 55 (2): 108-133. doi: 10.1016/j. survophthal. 2009.07. 005.

6. Schalnus R. Topical nonsteroidal anti-inflammatory therapy in ophthalmology. Ophthalmologica. 2003; 217 (2): 89-98. doi: $10.1159 / 000068563$ 


\section{Original Research Article}

7. Cho H, Wolf KJ, Wolf EJ. Management of ocular inflammation and pain following cataract surgery: focus on bromfenac ophthalmic solution. Clin Ophthalmol. 2009; 3:199-210. doi: 10.2147/opth.s4806

8. Baklayan GA, Patterson HM, Song CK, Gow JA, McNamara TR. 24-hour evaluation of the ocular distribution of (14)C-labeled bromfenac following topical instillation into the eyes of New Zealand White rabbits. J Ocul Pharmacol Ther. 2008;24(4):392-398. doi: 10.1089/jop.2007.0082.

9. Lane SS. Nepafenac: a unique nonsteroidal prodrug. Int Ophthalmol Clin. 2006;46(4):13-20. doi: 10. 1097/ 01.iio.0000212129.53019.49.

10. Walters T, Raizman M, Ernest P,Gayton JL, Lehmann RP. In vivo pharmacokinetics and in vitro pharmacodynamics of nepafenac, amfenac, ketorolac, and bromfenac. J Cataract Refract Surg. 2007; 33 (9): 1539-1545. doi: 10. 1016 /j. jers. 2007. 05. 015.

11. Roberts CW. Comparison of diclofenac sodium and flurbiprofen for inhibition of surgically induced miosis. J Cataract Refract Surg.1996;22(1):780-787. doi: 10. 1016/ s0886-3350(96)80162-3.

12. Gimbel H, Van Westenbrugge J, Cheetham JK, DeGryse R, Garcia CG. Intraocular Availability and Pupillary Effect of Flurbiprofen and Indomethacin During Cataract Surgery. J Cataract Refract Surg. 1996; 22(4): 474-479. doi: 10. 1016/ s0886-3350 (96) 800 $45-9$

13. Solomon KD, Turkalj JW, Whiteside SB, Stewart JA, Apple DJ. Topical $0.5 \%$ ketorolac vs. $0.03 \%$ flurbiprofen for inhibition of miosis during cataract surgery.Arch Ophthalmol. 1997;115(9):1119-1122. doi: 10.1001/archopht.1997.01100160289004

14. Atanis R, Tuaño PM, Vicencio J, Martinez JM, Verzosa L. Effect of topical ketorolac tromethamine and topical nepafenac on maintaining pupillary dilation during phacoemulsification. Philipp J Ophthalmol. $2011 ; 36(1): 23-27$.

15. Sarkar S, Mondal K.K, Roy S.S, Gayen S,Ghosh A and De R.R. Comparison of preoperative nepafenac $(0.1 \%)$ and flurbiprofen $(0.03 \%)$ eye drops in maintaining mydriasis during small incision cataract surgery in patients with senile cataract: A randomized, double-blind study. Ind J Pharmacology. 2015;47(5): 491-495. doi: 10.4103/0253-7613.165201.
16. Prakash S, Bhandare B, Satyanarayana V. and Kumar K. A comparative study on efficacy of nepafenac and flurbiprofen in maintenance of intraoperative mydriasis during cataract surgery: an open label randomized controlled trial. Int $\mathrm{J}$ Basic Clinic Pharmacol. 2018; 7 (4): 617-621. doi: http:// dx.doi. org/ 10. 18203/ 2319-2003. Ijbcp 2018 1002

17. Bansal G, Gupta S, Kumar S and Kansal S. Comparison of the effect of topical bromfenac with nepafenac in maintaining mydriasis during cataract surgery. DJO. 2015;26:97-100. doi:http://dx.doi.org/10. 7869/djo.146.

18.Cervantes-CG, Sanchez-Castro YG, Orozco-CM, Mendoza SE, Velasco BC. Inhibition of surgically induced miosis and prevention of postoperative macular edema with nepafenac. Clin Ophthalmol. 2009;3:219226.

19. Chen H, Lin H, Chen W, Zhang B, Xiang W, Li J, Chen W Topical $0.1 \%$ Bromfenac Sodium for Intraoperative Miosis Prevention and Prostaglandin $\mathrm{E}_{2}$ Inhibition in Femtosecond Laser-Assisted Cataract Surgery. J Ocul Pharmacol Ther. 2017;33(3):193-201. doi: 10.1089/jop.2016.0114.

20. Kida T, Ogawa T, McNamara TR, Song CK, Gow JA. Evaluations of the human COX-2 Inhibition for amfenac, bromfenac, diclofenac, and ketorolac. Paper presented at: American Society of Cataract and Refractive Surgery Symposium on cataract, IOL, and Refractive Surgery;2007.

21. Lane SS, Modi SS, Lehmann RP, Holland EJ. Nepafenac ophthalmic suspension $0.1 \%$ for the prevention and treatment of ocular inflammation associated with cataract surgery. J Cataract Refract Surg. 2007; 33 (1): 53-58. doi: 10.1016/j.jcrs.2006. 08. 043.

22. Stewart WC, Stewart R, Maxwell WA. Preoperative and postoperative clinical evaluation of nepafenac $0.1 \%$ ophthalmic suspension for post cataract inflammation. Presented at: American Society of Cataract and Refractive Surgery;2005.

23. Malik A, Sadafale A, Gupta Y.K and Gupta A. A comparative study of various topical non-steroidal antiinflammatory drugs to steroid drops for control of post cataract surgery inflammation. Oman J Ophthalmol. 2016; 9 (3): 150-156. doi: 10. 4103/ 0974-620X. 192 268 . 


\section{Original Research Article}

24.Silverstein SM, Cable MG, Sadri E, Peace JH, Fong R, Chandler SP, Gow JA, Klier SM, McNamara TR; Once daily dosing of bromfenac ophthalmic solution $0.09 \%$ for postoperative ocular inflammation and pain. Curr Med Res Opin. 2011;27(9): 1693-703. doi: 10. 1185 / 03007995
25. Gaynes BI, Fiscella R. Topical nonsteroidal antiinflammatory drugs for ophthalmic use: a safety review. Drug Saf. 2002;25(4):233-250. doi: 10.2165/00002018200225040-00002.

\section{How to cite this article?}

Minj A, Satapathy J, Kumar A. The importance of preoperative topical non-steroidal antiinflammatory agents in cataract surgery- an open label prospective randomised comparative study. Trop J Ophthalmol Otolaryngol.2019; 4(5):334-340. doi:10.17511/jooo.2019.i05.05 